\title{
The lemur syndrome unresolved: extreme male reproductive skew in sifakas (Propithecus verreauxi), a sexually monomorphic primate with female dominance
}

\author{
Peter M. Kappeler • Livia Schäffler
}

Received: 13 March 2007 /Revised: 19 November 2007 / Accepted: 20 November 2007 / Published online: 18 December 2007

(C) The Author(s) 2007

\begin{abstract}
The primates of Madagascar (Lemuriformes) are unusual among mammals in that polygynous species lack sexual dimorphism, and females dominate males socially in most species. Moreover, lemur groups are relatively small and characterized by even adult sex ratios despite the fact that one male should be able to exclude other males from the group. One hypothesis to explain this combination of behavioral, morphological, and demographic traits (the "lemur syndrome") postulates that male-male competition is relaxed and, hence, variance in male reproductive success is low. Reproductive skew theory provides a framework for testing this and several related predictions about lemur social evolution. Specifically, low reproductive skew is also predicted if dominant males or adult females make reproductive concessions to subordinates or if the latter group successfully pursues alternative reproductive tactics. However, suitable data on paternity, demography, and behavior for a conclusive test of these predictions have not been available in the past. In this paper, we show that male reproductive success in ten groups of Verreaux's sifakas (Propithecus verreauxi) was extremely skewed in favor of the dominant male over 9 years. Our genetic analyses also revealed that more than a third of all groups are effectively harem groups because only one male was unrelated to the resident female(s). In groups with two or more non-natal males, the dominant sired $91 \%$ of 33 infants. Together, males pursuing one of several alternative reproductive tactics, such as roaming among several
\end{abstract}

Communicated by J. Setchell

P. M. Kappeler $(\varangle) \cdot$ L. Schäffler

Department of Behavioral Ecology and Sociobiology,

German Primate Center,

Kellnerweg 4,

37077 Göttingen, Germany

e-mail: pkappel@gwdg.de groups or immigrating peacefully, sired only $11 \%$ of infants. Thus, female sifakas do not control group composition by offering reproductive opportunities to subordinate males as staying incentives, intrasexual selection is not relaxed, and dominant males prevail in a tug-of-war over subordinate males. Because male reproductive skew in sifakas is even more pronounced than in harem-living anthropoids studied to date, intrasexual selection is clearly not relaxed, and the lemur syndrome is more puzzling than ever.

Keywords Reproductive skew - Sexual selection - Paternity · Sexual conflict $\cdot$ Propithecus verreauxi

\section{Introduction}

In most animal societies, reproductive success is distributed unequally among individuals. The resulting patterns of reproductive skew have been analyzed within the framework of theoretical models that emphasize the relative importance of various social, ecological, and genetic factors in determining asymmetries in reproduction (Vehrencamp 1983; Emlen 1995; Clutton-Brock 1998; Reeve et al. 1998; Johnstone 2000). Individual variability in intrinsic competitive ability features prominently in limited control (or tug-of-war) models, which assume that reproduction by subordinates is the result of successful resistance to the dominants' attempt at monopolizing reproduction (Reeve et al. 1998). In contrast, concession (or transactional) models assume that reproduction is controlled by the dominant, but reproductive skew is reduced as a result of the dominants' offering of staying incentives in the form of reproductive opportunities because the dominants' fitness is enhanced by the presence of subordinates (Reeve and Ratnieks 1993). Staying incentives should be granted differentially, 
depending on the relatedness between dominant and subordinate, as well as the availability of alternative reproductive options for subordinates outside the group (Johnstone 2000).

Previous studies have provided support for both types of models (Clutton-Brock 1998; Reeve et al. 1998), and the latest modeling developments have therefore synthesized these two models (see "bordered tug-of-war model": Reeve and Shen 2006). Most studies to date have focused on reproductive skew among females, not only particularly in insects and birds (Reeve and Keller 2001; Haydock and Koenig 2002) but also in mammals (Cooney and Bennett 2000; Clutton-Brock et al. 2001; Gerlach and Bartmann 2002; Gilchrist 2006; Young et al. 2006). Male reproductive skew, however, has only been studied in a few mammals (Garnier et al. 2001; Engh et al. 2002; Alberts et al. 2003; Widdig et al. 2004; Bradley et al. 2005), even though reproductive competition is intimately linked to patterns of parental investment, which predispose male mammals towards higher potential reproductive rates, and, hence, competition over access to fertile females (Williams 1966; Trivers 1974; Clutton-Brock and Parker 1992).

Depending on the spatio-temporal distribution and absolute number of receptive females (Emlen and Oring 1977), male mammals employ any combination of different pre- and post-copulatory mechanisms to compete among each other, including monopolization, dominance, consortships, sperm competition, and several alternative tactics (Clutton-Brock 1989; Coltman et al. 1999; Setchell 2003). The relative importance of these mechanisms among species with different mating systems is correlated with predictable patterns of sexual dimorphism, relative testes size, and adult sex ratios (Clutton-Brock et al. 1977; Harvey et al. 1978). Moreover, as revealed by a comparative study in primates, male-male competition is also sensitive to the number of competitors, because male mating skew decreases as the number of males increases (Kutsukake and Nunn 2006). Importantly, as demonstrated for anthropoid primates, groups of up to five or six females can typically be monopolized by a single male (Mitani et al. 1996; Nunn 1999), and these species tend to have the most pronounced sexual dimorphism (Alexander et al. 1979; Jarman 1983; Plavcan 2001). Females may break this male monopolization by increasing their estrous synchrony (Nunn 1999), but a comparative study across primates found no relationship between the degree of male mating skew and the overlap in female receptivity (Kutsukake and Nunn 2006).

Recent studies suggested that intrasexual competition among females can also generate selection pressures favoring competitive ability (Clutton-Brock et al. 2006). Female breeding success may be strongly affected by behavioral and morphological traits in cooperative or eusocial mammals with high female reproductive skew, such as meerkats or naked mole-rats, and also in other species with larger and more aggressive females, such as spotted hyenas or many lemurs (see, e.g., Vick and Pereira 1989; East et al. 2003). As a result, sex differences in morphology and behavior may deviate from classical predictions of sexual selection theory and affect intersexual relations and the operation of sexual selection in unpredicted ways (Clutton-Brock et al. 2006). In particular, females may exert control over the distribution of paternity among males by providing staying incentives to subordinates in order to retain them in the group or to maximize the amount of care their offspring receive (Cant and Reeve 2002).

Lemur syndrome and predictions Group-living primates of Madagascar are unusual among mammals in that single males do not monopolize a small number $(<5)$ of adult females, so that social groups have on average even adult sex ratios (Kappeler 2000; Pochron and Wright 2003). Thus, lemur groups contain more subordinate males than expected for the number of adult females present (see Andelman 1986). Moreover, females tend to be larger and heavier than males, and they dominate males socially (Jolly 1966; Richard 1987; Kappeler 1993). In addition, breeding competition among female lemurs is unusually intense, including targeted aggression and eviction of close relatives (Vick and Pereira 1989; Pereira and Leigh 2003). Explaining this combination of traits - the "lemur syndrome"-has long posed a challenge to evolutionary anthropologists, and several hypotheses have been proposed to explain the even sex ratio, the lack of male-biased sexual dimorphism, and the evolution of female dominance (van Schaik and Kappeler 1996; Jolly 1998; Wright 1999; Richard et al. 2002). In this study, we test predictions of relevant key hypotheses for the first time with reproductive skew theory.

Sexual conflict over group composition (Hamilton 2000) lies at the heart of two hypotheses that attempt to explain these lemur idiosyncrasies. First, if intrasexual selection determines the number of rival males in a group, the presence of subordinate males may indicate that, following the logic of concession models (Reeve et al. 1998), dominant males derive a benefit from their presence. In this case, shared reproduction and, hence, reduced reproductive skew are predicted. Low reproductive skew is also predicted under tug-of-war models if subordinate males successfully pursue alternative reproductive tactics (Reeve et al. 1998). However, if dominants are unable to exclude rivals from a group of females, tug-of-war models predict high reproductive skew among co-resident males (CluttonBrock 1998). Second, it has also been suggested that female interests ultimately determine the number of males per group (van Schaik and Hörstermann 1994; Ostner and Kappeler 2004) and that selection on female competitive 
ability renders male-male competition effectively irrelevant (Kappeler 2000). Female lemurs typically copulate with most males present (e.g., Brockman and Whitten 1996; Ostner and Kappeler 2004; Eberle and Kappeler 2004), but it is unclear whether female polyandry is a result of females' dominance, the dominant males' tolerance, or their inability to prevent it. High male reproductive skew would argue against female control and their strategic use of mating incentives towards subordinate males, however (Cant and Reeve 2002; Engh et al. 2002).

Verreaux's sifakas (Propithecus verreauxi) are $3-\mathrm{kg}$ arboreal lemurs that live in groups of typically one to three adult females and about the same number of adult males (Richard et al. 2002). Dispersal is strongly male-biased (Richard et al. 1993), and males provide no paternal care apart from occasional infant grooming (Grieser 1992; Bastian and Brockman 2007). During their brief annual receptivity of about 1 day (range $30 \mathrm{~min}$ to 4 days; Brockman 1999), females, who dominate males (Richard and Nicoll 1987; see also Pochron et al. 2003), may mate with several males, sometimes including neighbors from adjacent groups or roaming males (Brockman and Whitten 1996; Brockman 1999). Infanticide by strange males following group takeovers is another male reproductive strategy (Lewis et al. 2003). One male in each group is dominant, has a large chest gland, and has significantly elevated testosterone levels during the mating season (Kraus et al. 1999; Lewis and van Schaik 2007), but there is no directional selection on male body mass or canine size (Lawler et al. 2005). However, because access to receptive females is independent of the occurrence or outcome of male aggression and may be mediated in part by sperm competition (see Pochron and Wright 2005), the sifaka mating system has been characterized as female-controlled polygyny (Richard 1992). In this paper, we present genetic, behavioral, and demographic data from a 9-year study of ten social groups to characterize male reproductive skew in this sexually monomorphic primate with female dominance. Low reproductive skew would be compatible with predictions of concession models from the perspective of dominant males or adult females, and low skew is also predicted under tug-of-war models if subordinates pursue alternative reproductive tactics. High reproductive skew, on the other hand, would be in line with predictions of strict tug-of-war models.

\section{Materials and methods}

Study population

Our study was conducted in Kirindy Forest, a dry deciduous forest located approximately $60 \mathrm{~km}$ north of
Morondava in central western Madagascar, where the German Primate Center has operated a research station since 1993 (Sorg et al. 2003). Beginning with six groups in March 1995 (Table 1), members of eventually ten adjacent groups of $P$. verreauxi verreauxi inhabiting a 48-ha study site equipped with $37 \mathrm{~km}$ of small foot trails have been habituated and marked individually with nylon collars and unique pendants. During short anesthesia following blowpipe darting in March and/or September of every year, individuals have been subjected to standard field measurements (body mass, body length, canine length, testes size, and reproductive status; see Glander et al. 1992; Kappeler 1997), and a small tissue sample was taken from the ears for later DNA extraction. Between 1995 and 2003, a total of 148 individuals, including 56 new infants that survived their first year, were censused on average several times each week. As a result, all births, deaths, emigrations, and immigrations were registered and timed to within a few days. Morphometric data collected on adult ( $>5$ years) individuals at the end of the mating season (i.e., in March) were used for analyses of variation in physical traits, including body condition (body mass/body length). Behavioral data gathered during censuses or during specific studies were used to determine dominance relations within groups based on decided agonistic interactions (Pereira and Kappeler 1997) involving unidirectional exchanges of submissive "spat" vocalizations (Richard and Heimbuch 1975). Male dominance relationships were determined or re-evaluated for every annual mating season.

\section{Relatedness and kinship analyses}

Approximately $0.5 \mathrm{~g}$ of tissue was used to extract DNA from the tissue samples, following the QIAGEN DNA Mini Kit for Tissue Samples protocol. DNA concentration was estimated by ethidium bromide fluorescence on a $5 \%$

Table 1 Group history of the study population

\begin{tabular}{|c|c|c|c|c|c|c|c|c|c|c|}
\hline \multirow{2}{*}{$\frac{\text { Year }}{1995}$} & \multicolumn{10}{|c|}{ Groups } \\
\hline & A & B & $\mathrm{C}$ & D & E & $\mathrm{F}$ & & & & \\
\hline 1996 & A & B & $\mathrm{C}$ & D & E & $\mathrm{F}$ & G & & & \\
\hline 1997 & A & B & $\mathrm{C}$ & D & E & $\mathrm{F}$ & $\mathrm{G}$ & $\mathrm{H}$ & & \\
\hline 1998 & A & B & $\mathrm{C}$ & & E & $\mathrm{F}$ & $\mathrm{G}$ & $\mathrm{H}$ & $\mathrm{J}$ & \\
\hline 1999 & A & B & $\mathrm{C}$ & & E & $\mathrm{F}$ & $\mathrm{G}$ & $\mathrm{H}$ & $\mathrm{J}$ & K \\
\hline 2000 & A & B & $\mathrm{C}$ & & E & $\mathrm{F}$ & $\mathrm{G}$ & $\mathrm{H}$ & $\mathrm{J}$ & K \\
\hline 2001 & A & B & $\mathrm{C}$ & & E & $\mathrm{F}$ & $\mathrm{G}$ & $\mathrm{H}$ & $\mathrm{J}$ & K \\
\hline 2002 & A & B & $\mathrm{C}$ & & E & $\mathrm{F}$ & $\mathrm{G}$ & $\mathrm{H}$ & $\mathrm{J}$ & K \\
\hline 2003 & A & B & $\mathrm{C}$ & & E & $\mathrm{F}$ & G & $\mathrm{H}$ & $\mathrm{J}$ & $\mathrm{K}$ \\
\hline
\end{tabular}

The study of $P$. verreauxi was initiated at Kirindy with groups A-F in 1995. Between 1995 and 1999, groups G-K were successively added to the study population. Group D went extinct in 1997 following predation and emigration of all group members 
agarose gel. Samples that did not yield sufficient amounts of DNA were amplified by whole genome amplification. Template DNA samples were stored at $-20^{\circ} \mathrm{C}$ for further processing. Fifteen microsatellite markers were chosen for parentage analysis: Pvc 9.2, Pvc 10.1, Pvc 15, Pvc x, Pvc a1, Mm03 (\# NCBI: AJ420851-855, AJ420847; Wimmer 2000), P.V. 1, P.V. 6, P.V. 14, P.V. 15, P.V. 16 (no NCBI notation; Lawler et al. 2001), 47HD Z215, 47HD Z422, 47HD Z682, and 47HD Z720 (\# NCBI: AY045554; AF406741; AY 045557; AY045558; Mayor et al. 2002). One primer of each pair was labeled with a fluorescent dye (HEX, TAMRA, FAM, or TET). Polymerase chain reaction products were estimated for their DNA concentration and for analysis on the ABI 3100-Avant Capillary Sequencer. Signals were interpreted manually using the software Genemapper 3.5.

Genotypes were analyzed for parentage with Cervus 2.0. The program determines the most likely parents by a combined approach of (1) parentage exclusion based on individual genotypes and (2) maximum likelihood combination of parents based on allele frequency data in the population. The most likely sires are indicated by the highest logarithm of odds (LOD) values. Confidence intervals are calculated by comparing the difference in LOD values of the most likely candidate parents, given as $\Delta$-value, with the distribution of simulated $\Delta$-values. Simulations to determine $\Delta$-values were run 50,000 times and implemented results of the prior allele frequency analyses, the rate of mistyping error (estimated to be $1 \%$ ), and the proportion of males sampled in the population. As the latter parameter increased with time of the study, it was determined per year and set to 0.6 for the period 1993 1996, 0.8 for 1997-1999, 0.9 for 2000-2002, and 0.95 for 2003. Confidence levels for paternity assignments were set to $85 \%$ and $98 \%$.

Paternity analyses for the years 1996 to 2003 were conducted with one parent known, as maternity was known from demographic censuses and checked against genetic data. Because sifaka mating is cryptic and difficult to observe at Kirindy, behavioral data could not be used to generate hypotheses about paternity. For individuals born between 1993 and 1995, which could be identified as juveniles at first capture, parentage analyses were conducted with none of the parents known. For each year, a specific set of candidate fathers formed the basis for paternity assignments (one-parent-known analysis). The set consisted of all adult males present in the population in a given year and was applied to all offspring born into the population in that year. Therefore, the entire male population was considered as potential fathers, independent of group affiliation. As males were observed mounting adult females as early as 2 years of age, they were considered as possible sires in the third mating season following their birth. Males were also included as candidate fathers after their presumed emigration because death could not always be established with certainty after a male disappeared. Females were included as candidate mothers from their fourth mating season onwards. In most cases, typing of 15 loci revealed only one mother-father-offspring triad without a mismatch. How parentage was assigned in the few exceptional cases is detailed below.

\section{Results}

Demography and morphometrics

Based on the distribution of birth dates, the mating season of Kirindy sifakas was defined as the period between January 15th and March 31st, with most females giving birth every year (Kappeler, unpublished data). The composition of the study groups was determined for each mating season, totaling 68 group-years. Groups of $P$. verreauxi contained on average (mean \pm SE) $1.8 \pm 0.7$ adult females and $2.3 \pm 0.8$ adult males during the mating season. The number of adult males varied between one and four, but the average number of adult females did not vary significantly as a function of the number of males (KruskalWallis $\left.H_{3,66}=1.71, p=0.63\right)$. Natal males emigrated at an average age of $66.2 \pm 16.4(N=6$; minimum 32 , maximum 139) months. Based on long-term demographic records and the genetic analyses, each adult male was assigned to one of six classes, which may represent different reproductive tactics, for each group-year ( $N=164$ male group-years): natal male $(22 \%)$, born in the group under study; established resident (47\%), more than 1 year exclusive group membership after immigration; recent immigrants (9\%), immigrated into the group within the last year without aggression; takeover $(6 \%)$, evicted former resident within the last year; roamer (12\%), without exclusive group membership; and males of unknown status (4\%).

During the mating season, there was no significant sexual dimorphism, even though adult females were slightly heavier than males (mean $\pm \mathrm{SE}$, females $3,256 \pm$ $83 \mathrm{~g}(N=24)$; males $3,194 \pm 67 \mathrm{~g}(N=23) ; t_{45}=0.57, p=$ $0.56)$, and males had on average slightly longer canines (females, $7.8 \pm 0.2 \mathrm{~mm}(N=22)$; males, $8.4 \pm 0.2 \mathrm{~mm}(N=$ 22); $\left.t_{42}=1.81, p=0.07\right)$.

\section{Paternity and reproductive skew}

Together, the 15 markers yielded an exclusion probability of 0.9996 when no parent was known, and 0.999998 when one parent was known. The proportion of all loci typed was $85 \%$. Microsatellites were characterized by four to 11 alleles and a mean heterozygosity of 0.758 (minimum- 
maximum 0.614-0.912; no significant deviations from Hardy-Weinberg equilibrium). Parentage was determined for a total of 64 offspring born to 20 mothers in ten groups between 1993 and 2003 that survived to at least 6 months of age. In one exceptional case, no tissue sample was available for one of the two females present in the group that year. Nevertheless, parentage was assigned to that female and the only male in the population without any mismatches, as maternity could be excluded for the other female. For $71.4 \%$ of 63 offspring, sires were determined by likelihood analysis with $98 \%$ confidence; for $15.9 \%$ of offspring, confidence was between $98 \%$ and $85 \%$, and in only one case confidence was smaller than $85 \%$. Of 63 parentages, $92.1 \%$ could be assigned without any mismatch and $7.9 \%$ (five infants) with one mismatch. One of the mismatches is likely to be due to allelic drop-out (both parents homozygote on the mismatching loci), with the other four cases might be attributed to mutation events or genotyping errors. There was no other combination of parents with an equally good fit in $82.5 \%$ (52 infants; 50 of those without mismatch, two with one mismatch). In $12.7 \%$ (eight infants) of cases, there was another triad with the same number of mismatches (seven with no mismatch, one with one mismatch), in two cases there were two (one with one, one with no mismatch), and in one case seven (one mismatch). Paternity exclusion between candidate fathers with equal number of mismatches was based on demographic information, so that inbreeding was excluded (see below) and parentages made "biological sense". Specifically, in eight cases, the most likely sire suggested by the analysis was excluded because this was an older brother of the offspring in question. These decisions were confirmed by LOD scores in seven cases. In two cases, paternity exclusion was solely based on LOD scores or demography, respectively. Paternities were then assigned to male classes and compared to expected values, as well as among males with different dominance status, age, and physical characteristics.

Using only offspring born into groups with known composition during the preceding mating season, we found that $37 \%$ of the corresponding 54 infants were effectively sired in harem groups, because these groups contained only one immigrant male with a mitochondrial haplotype that diverged from that of the resident female(s) (Kappeler, unpublished data). In years in which groups contained two or more males during the mating season, infants were sired by the behaviorally dominant male in 31 out of 34 cases (91.2\%); reproductive skew is therefore extremely pronounced (Fig. 1). Reproductively successful males had, on average, larger testes $\left(U_{15,6}=10.5, p=0.005\right)$ and longer canines $\left(U_{22,13}=69.5, p=0.01\right)$ than non-reproducing coresident males, but they were not in significantly better body condition $\left(U_{22,11}=79.0, p=0.11\right)$. The possible effects of age on morphology and reproductive success could not

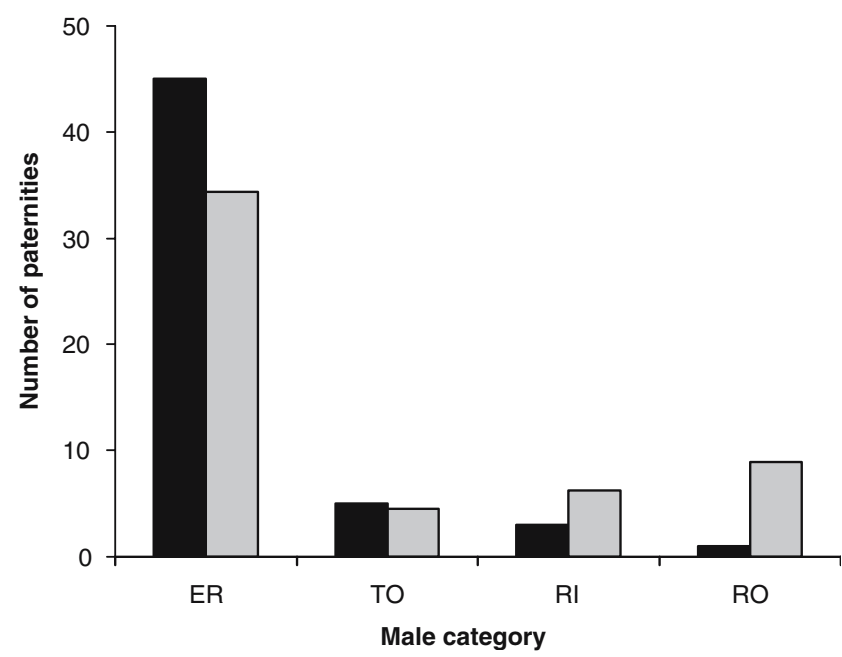

Fig. 1 Distribution of reproductive success among males pursuing different reproductive tactics. Observed (black) and expected (gray) number of paternities attributed to established residents $(E R)$, takeover males $(T O)$, recent immigrants $(R I)$, and roaming males $(R O)$. Expected values are based on the proportion of males in the population across all mating seasons

be statistically controlled because the exact ages of most adult males were unknown. Minimum mean tenure length of successful males was $62.4 \pm 10.1$ months $(N=15)$, significantly longer $\left(t_{33}=3.78, p=0.0006\right)$ than the mean residency duration of reproductively unsuccessful males (24.4 \pm 4.3 months).

Comparing reproductive success of males employing different tactics, we found that established residents were significantly more successful than expected, based on their representation in the population $\left(\chi_{(3)}^{2}=12.03, p<0.01\right.$, excluding natal and unknown status males), because they sired the vast majority of offspring $(83.3 \% ; N=54$; Fig. 2$)$. Five paternities were claimed by males who aggressively took over a group: one male sired infants with both resident females immediately after his takeover, one male ousted the established resident a year after his immigration and reproduced successfully in the subsequent year, and one male sired one infant not until the year after his takeover. In one case, a takeover male and a recent immigrant male, who were not related to each other, shared the two paternities in one group in 1 year. Only two other infants were sired by recent immigrant males: one male sired an infant following his immigration in 1997; all other seven offspring born to two females in that group between 1996 and 2003 were sired by another established resident, however. One young female produced her first offspring with a recent immigrant during her father's continued tenure. Similarly, a daughter of an established resident had her first infant sired by a roaming male from a neighboring group during her father's ongoing tenure. Males never 


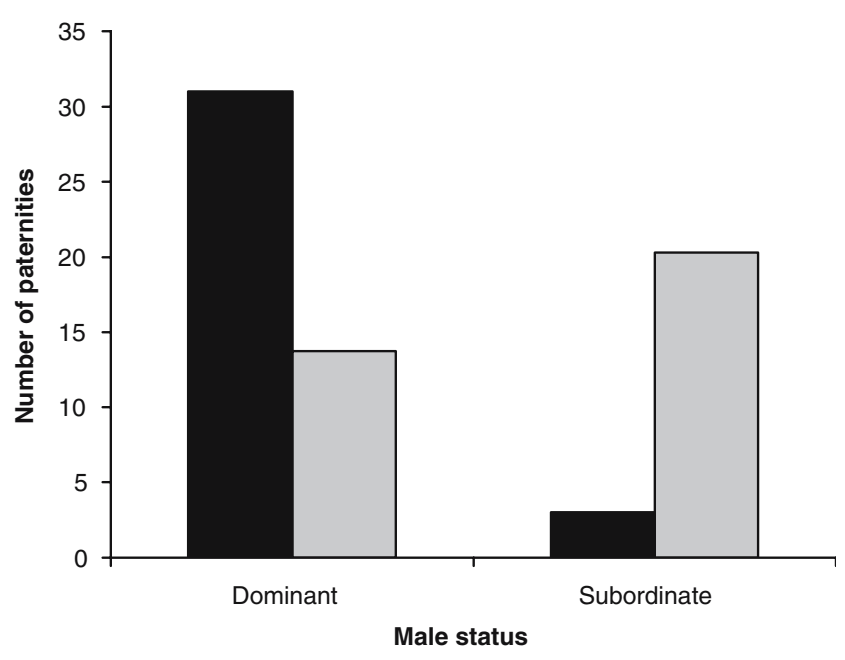

Fig. 2 Behavioral determinants of male reproductive success. Of 54 infants, $37 \%$ were sired in groups monopolized by one non-natal male. Of the remaining 34 infants sired in multi-male groups, significantly more infants (black) than expected (gray) were sired by the dominant (see text). Expected values are based on the number of co-resident adult non-natal males per mating season in each group

reproduced in their natal group, not even in one unusual case when a mother of two sexually mature males died and was replaced by an unrelated immigrant female.

\section{Discussion}

Our results revealed three important insights into lemur social evolution that are also of general interest because they illuminate how reproductive skew interacts with fundamental socioecological variables, including optimal group size and composition, delayed dispersal, mating tactics, and sexual conflict (e.g., Davies 1985, 2000; Clutton-Brock 2002; Clutton-Brock and Isvaran 2006).

First, an unexpectedly large proportion (in our sample $37 \%$ ) of multi-male groups are in fact single-male groups because all but one adult male were natal males, who apparently delayed natal dispersal long after sexual maturity (Richard et al. 2002). Previous short-term behavioral studies or censuses could not identify these adult males as natal, thereby underestimating assessments of males' monopolization potential (cf. Kappeler 2000). This observation raises the question why some natal males delay dispersal well beyond sexual maturity. Possible explanations include the attainment of superior physical condition that may increase their probability of a successful takeover (Alberts and Altmann 1995) and benefits from group augmentation, including a reduced takeover risk of their natal group (Ostner and Kappeler 2004).

It is also puzzling why there has been no strong selection on male morphological traits that contribute to male monopolization potential. Even though there is statistically significant morphological variation among males that correlates with variation in reproductive success, it has not resulted in biologically meaningful male-biased sexual dimorphism over evolutionary times. In another sifaka population at Beza Mahafaly, only directional selection on male limb length could be demonstrated (Lawler et al. 2005), suggesting that perhaps locomotor agility, and not size or strength, is of prime importance in male combat in this arboreal species (see also Thoren et al. 2006).

Second, male reproductive skew in groups with two or more non-natal males was heavily biased in favor of dominant males. This result suggests that dominant males do not provide subordinates with staying incentives in the form of reproductive opportunities. Instead, dominant males are able to monopolize reproduction almost completely. In a cross-sectional genetic study of gentle lemur (Hapalemur griseus) population, 91\% of infants were also sired by a single resident male (Nievergelt et al. 2002), whereas dominant males reaped $67 \%$ of all paternities in redfronted lemurs (Wimmer and Kappeler 2002), suggesting the existence of similar processes in other lemur taxa. Because the degree of male reproductive skew observed in this sifaka population equals or exceeds that of highly sexually dimorphic anthropoids living in highly polygynous systems, such as mountain gorillas (Bradley et al. 2005), orang-utans (Utami et al. 2002), mandrills (Charpentier et al. 2005), patas monkeys (Ohsawa et al. 1993), and red howler monkeys (Pope 1990), mechanisms other than exclusion and physical superiority are primary determinants of reproductive success of male sifaka. Perhaps dominant males are particularly effective at mate guarding at crucial times during the females' estrus (Clutton-Brock and Isvaran 2006) because their testes are clearly not adapted to intense sperm competition when examined from a comparative perspective (Kappeler 1997). Cryptic female choice of dominant males may be another mechanism that could generate the observed distribution of paternities, but this mechanism remains poorly studied in primates and other mammals (Dixson 2002; Reeder 2003).

Most of the few exceptional cases of paternity loss by the dominant male could be attributed to inbreeding avoidance or unsettled dominance relations. The cases where females apparently targeted an unrelated male for paternity during their father's ongoing tenure suggest that females are sensitive to the risk of inbreeding and provide justification for our decision to exclude older brothers as candidate fathers. Paternity loss by the dominant male could also be due to female estrous synchrony. In six out of ten cases in which two females reproduced within a group in the same year, female estruses occurred within 4 days of each other, so that female estrous synchrony may occasionally reduce male monopolization potential (see also 
Brockman 1999). However, the dominant male secured all corresponding paternities.

Given this observed reproductive skew in favor of dominant males, it remains puzzling why subordinate males do not attempt takeovers more often. One possibility is that they are queuing for the alpha position (Kokko and Johnstone 1999; Cant and English 2006), as for example mountain gorillas (Bradley et al. 2005) or spotted hyenas (East and Hofer 2001), but adult mortality rates are low, and sifaka life span may reach up to 30 years (Richard et al. 2002). The potential success of this tactic can therefore not be evaluated with the available data. Information on complete individual life histories, including lifetime reproductive success, will be required to confirm the conclusion of this study that concessions are unimportant in structuring male reproductive competition more thoroughly. A second theoretical possibility is that subordinate males benefit indirectly because of their close relatedness with the dominant. The degree of relatedness between dominants and subordinates is in fact important for testing different reproductive skew models, but the tug-of-war models are insensitive to relatedness, and coresident non-natal males in our study population were virtually always unrelated, so that we could not evaluate the effect of relatedness with the available data.

Finally, the common failure of most subordinate males to reproduce successfully, irrespective of which alternative tactic they pursue, suggests that adult females do not control group composition by offering subordinate males staying incentives in the form of reproductive opportunities (cf. Hamilton 2000; Cant and Reeve 2002). Polyandrous matings by females therefore only rarely compromise the dominant male's reproductive success, unlike in spotted hyenas, for example (Engh et al. 2002), and may be part of females' reproductive tactics to maximize their fitness (Fisher et al. 2006; Hoffman et al. 2007). Theoretically, female sifakas could benefit from the presence of multiple males, e.g., in the form of improved mate choice, reduced vigilance (van Schaik and Hörstermann 1994), and predator mobbing (Karpanty 2006), as well as reduced takeover risk, as has been suggested for other lemurs (Ostner and Kappeler 2004). However, subordinate males apparently do not benefit directly from these potential services, as suggested by increased mortality rates in larger groups (Kappeler, unpublished data). Hence, neither males nor females seem to enjoy benefits of group augmentation in terms of improved survival, even though such benefits are expected to be greatest at such small group sizes (Hamilton 1971). Thus, despite their ability to dominate males, female sifakas do not appear to influence group composition and the distribution of paternity to the extent observed in other mammals with powerful females (East et al. 2003), but there may be interesting intraspecific variation in these costs and benefits because a recent study at Beza Mahafaly documented that the majority ( 29 of 52) of males there sired at least one offspring outside their resident group (Lawler 2007).

In conclusion, male-male competition among sifakas is intense and male reproductive success is highly skewed, but the attendant evolutionary consequences for demography, male behavior, and morphology are not realized. The observed pattern of reproductive skew is consistent with a tug-of-war scenario, and there was no evidence for concessions towards subordinate males. Pending formal selection gradient analyses, the hypothesis that relaxed intrasexual selection on males, compared to females, has facilitated the evolution of the lemur syndrome can therefore be provisionally rejected. However, given the present results, this deviation from sexual selection theory is more puzzling than ever, so that lemurs continue to challenge mammalian behavioral ecologists to adopt broader perspectives in the study of sex differences and sexual selection.

Acknowledgements We thank the Malagasy Ministère de l'Environnement et des Eaux et Forêts, the Département Biologie Animale de l'Université d'Antanannarivo, and the Centre de Formation Professionelle Forestière Morondava for authorizing and supporting our longterm research in Kirindy. We are grateful for assistance in the field from Enafa, Edidier, L. Razafimanantsoa, R. Rasoloarison, T. Andrianjanahary, and the rest of the Equipe DPZ, as well as for assistance in the lab from M. Eberle, C. Roos, L. Walter, and C. Oberdieck. Thanks to J. Setchell, M. Port and three anonymous referees, who improved an earlier version of this manuscript with their constructive comments. Financial support was provided by the Deutsche Forschungsgemeinschaft (Ka 1082/1-3) and the Deutsches Primatenzentrum.

Open Access This article is distributed under the terms of the Creative Commons Attribution Noncommercial License which permits any noncommercial use, distribution, and reproduction in any medium, provided the original author(s) and source are credited.

\section{References}

Alberts S, Altmann J (1995) Balancing costs and opportunities: dispersal in male baboons. Am Nat 145:279-306

Alberts SC, Watts HE, Altmann J (2003) Queuing and queue-jumping: long-term patterns of reproductive skew in male savannah baboons, Papio cynocephalus. Anim Behav 65:821-840

Alexander RD, Hoogland JL, Howard RD, Noonan KM, Sherman PW (1979) Sexual dimorphism and breeding systems in pinnipeds, ungulates, primates, and humans. In: Chagnon NA, Irons W (eds) Evolutionary biology and human social behavior. Duxbury, North Scituate, MA, pp 402-435

Andelman SJ (1986) Ecological and social determinants of cercopithecine mating patterns. In: Rubenstein DI, Wrangham RW (eds) Ecological aspects of social evolution: birds and mammals. Princeton University Press, Princeton, NJ, pp 201-216

Bastian ML, Brockman DK (2007) Paternal care in Propithecus verreauxi coquereli. Int J Primatol 28:305-313

Bradley BJ, Robbins MM, Williamson EA, Steklis HD, Steklis NG, Eckhardt N, Boesch C, Vigilant L (2005) Mountain gorilla tugof-war: silverbacks have limited control over reproduction in multimale groups. Proc Natl Acad Sci USA 102:9418-9423

Brockman DK (1999) Reproductive behavior of female Propithecus verreauxi at Beza Mahafaly, Madagascar. Int J Primatol 20:375-398 
Brockman DK, Whitten PL (1996) Reproduction in free-ranging Propithecus verreauxi: estrus and the relationship between multiple partner matings and fertilizations. Am J Phys Anthropol 100:57-69

Cant MA, English S (2006) Stable group size in cooperative breeders: the role of inheritance and reproductive skew. Behav Ecol 17:560-568

Cant MA, Reeve HK (2002) Female control of the distribution of paternity in cooperative breeders. Am Nat 160:602-611

Charpentier M, Peignot P, Hossaert-McKey M, Gimenez O, Setchell JM, Wickings EJ (2005) Constraints on control: factors influencing reproductive success in male mandrills (Mandrillus sphinx). Behav Ecol 16:614-623

Clutton-Brock TH (1989) Mammalian mating systems. Proc R Soc Lond, B Biol Sci 236:339-372

Clutton-Brock TH (1998) Reproductive skew, concessions and limited control. Trends Ecol Evol 13:288-292

Clutton-Brock TH (2002) Breeding together: kin selection and mutualism in cooperative vertebrates. Science 296:69-72

Clutton-Brock TH, Isvaran K (2006) Paternity loss in contrasting mammalian societies. Biol Lett 2:513-516

Clutton-Brock TH, Parker GA (1992) Potential reproductive rates and the operation of sexual selection. Q Rev Biol 67:437-456

Clutton-Brock TH, Harvey PH, Rudder B (1977) Sexual dimorphism, socionomic sex ratio and body weight in primates. Nature 269:797-800

Clutton-Brock TH, Brotherton PNM, Russell AF, O, Riain MJ, Gaynor D, Kansky R, Griffin A, Manser M, Sharpe L, McIlrath GM, Small T, Monfort S (2001) Cooperation, control, and concession in meerkat groups. Science 291:478-481

Clutton-Brock TH, Hodge SJ, Spong G, Russell AF, Jordan NR, Bennett NC, Sharpe LL, Manser MB (2006) Intrasexual competition and sexual selection in cooperative mammals. Nature 444:1065-1068

Coltman DW, Bancroft DR, Robertson A, Smith JA, Clutton-Brock TH, Pemberton JM (1999) Male reproductive success in a promiscuous mammal: behavioral estimates compared with genetic paternity. Mol Ecol 8:1199-1209

Cooney R, Bennett NC (2000) Inbreeding avoidance and reproductive skew in a cooperative mammal. Proc R Soc Lond, B Biol Sci 267:801-806

Davies NB (1985) Cooperation and conflict among dunnocks, Prunella modularis, in a variable mating system. Anim Behav $33: 628-648$

Davies NB (2000) Multi-male breeding groups in birds: ecological causes and social conflict. In: Kappeler PM (ed) Primate males: causes and consequences of variation in group composition. Cambridge University Press, Cambridge, pp 11-20

Dixson AF (2002) Sexual selection by cryptic female choice and the evolution of primate sexuality. Evol Anthropol 11(1):195-199

East ML, Hofer H (2001) Male spotted hyenas (Crocuta crocuta) queue for status in social groups dominated by females. Behav Ecol 12:558-568

East ML, Burke T, Wilhelm K, Greig C, Hofer H (2003) Sexual conflicts in spotted hyenas: male and female mating tactics and their reproductive outcome with respect to age, social status and tenure. Proc R Soc Lond, B Biol Sci 270:1247-1254

Eberle M, Kappeler PM (2004) Selected polyandry: female choice and inter-sexual conflict in a small nocturnal solitary primate (Microcebus murinus). Behav Ecol Sociobiol 57:91-100

Emlen ST (1995) An evolutionary theory of the family. Proc Natl Acad Sci USA 92:8092-8099

Emlen ST, Oring LW (1977) Ecology, sexual selection, and the evolution of mating systems. Science 197:215-223

Engh AL, Funk SM, van Horn RC, Scribner KT, Bruford MW, Libants S, Szykman M, Smale L, Holekamp KE (2002) Reproductive skew among males in a female-dominated mammalian society. Behav Ecol 13:193-200
Fisher DO, Double MC, Blomberg SP, Jennions MD, Cockburn A (2006) Post-mating sexual selection increases lifetime fitness of polyandrous females in the wild. Nature 444:89-92

Garnier JN, Bruford MW, Goossens B (2001) Mating system and reproductive skew in the black rhinoceros. Mol Ecol 10:2031-2041

Gerlach G, Bartmann S (2002) Reproductive skew, costs, and benefits of cooperative breeding in female wood mice (Apodemus sylvaticus). Behav Ecol 13:408-418

Glander KE, Wright PC, Daniels PS, Merenlender AM (1992) Morphometrics and testicle size of six rainforest lemur species from southeastern Madagascar. J Hum Evol 22:1-17

Gilchrist J (2006) Reproductive success in a low skew, communal breeding mammal: the banded mongoose, Mungos mungos. Behav Ecol Sociobiol 60:854-863

Grieser B (1992) Infant development and parental care in two species of sifakas. Primates 33:305-314

Hamilton WD (1971) Geometry for the selfish herd. J Theor Biol 31:295-311

Hamilton IM (2000) Recruiters and joiners: using optimal skew theory to predict group size and the division of resources within groups of social foragers. Am Nat 155:684-695

Harvey PH, Kavanaugh M, Clutton-Brock TH (1978) Sexual dimorphism in primate teeth. J Zool 186:475-485

Haydock J, Koenig WD (2002) Reproductive skew in the polygynandrous acorn woodpecker. Proc Natl Acad Sci USA 99:7178-7183

Hoffman JI, Forcada J, Trathan PN, Amos W (2007) Female fur seals show active choice for males that are heterozygous and unrelated. Nature 445:912-914

Jarman PJ (1983) Mating system and sexual dimorphism in large, terrestrial, mammalian herbivores. Biol Rev 58:485-520

Johnstone RA (2000) Models of reproductive skew: a review and synthesis. Ethology 106:5-26

Jolly A (1966) Lemur behavior. University of Chicago Press, Chicago

Jolly A (1998) Pair-bonding, female aggression and the evolution of lemur societies. Folia Primatol 69(1):1-13

Kappeler PM (1993) Female dominance in primates and other mammals. In: Bateson PPG, Klopfer PH, Thompson NS (eds) Perspectives in ethology, vol 10. Behaviour and evolution. Plenum, New York, pp 143-158

Kappeler PM (1997) Intrasexual selection and testis size in strepsirhine primates. Behav Ecol 8:10-19

Kappeler PM (2000) Causes and consequences of unusual sex ratios among lemurs. In: Kappeler PM (ed) Primate males: causes and consequences of variation in group composition. Cambridge University Press, Cambridge, pp 55-63

Karpanty S (2006) Direct and indirect impacts of raptor predation on lemurs in southeastern Madagascar. Int J Primatol 27:239-261

Kokko H, Johnstone RA (1999) Social queuing in animal societies: a dynamic model of reproductive skew. Proc R Soc Lond, B Biol Sci 266:571-578

Kraus C, Heistermann M, Kappeler PM (1999) Physiological suppression of sexual function of subordinate males: a subtle form of intrasexual competition among male sifakas (Propithecus verreauxi)? Physiol Behav 66:855-861

Kutsukake N, Nunn CL (2006) Comparative tests of reproductive skew in male primates: the roles of demographic factors and incomplete control. Behav Ecol Sociobiol 60:695-706

Lawler RR (2007) Fitness and extra-group reproduction in male Verreaux's sifaka: an analysis of reproductive success from 1989-1999. Am J Phys Anthropol 132:267-277

Lawler RR, Richard AF, Riley MA (2001) Characterization and screening of microsatellite loci in a wild lemur population (Propithecus verreauxi verreauxi). Am J Primatol 55:253-259

Lawler RR, Richard AF, Riley MA (2005) Intrasexual selection in Verreaux's sifaka (Propithecus verreauxi verreauxi). J Hum Evol $48: 259-277$ 
Lewis RJ, van Schaik CP (2007) Bimorphism in male Verreaux's sifaka in the Kirindy Forest of Madagascar. Int J Primatol 28:159-182

Lewis RJ, Razafindrasamba SM, Tolojanahary JP (2003) Observed infanticide in a seasonal breeding prosimian (Propithecus verreauxi verreauxi) in Kirindy Forest, Madagascar. Folia Primatol 74:101-103

Mayor M, Sommer J, Huebinger R, Barber R, Louis E (2002) Characterization of seven microsatellite marker loci in a genus of Malagasy lemurs (Propithecus). Mol Ecol Notes 2:385-388

Mitani JC, Gros-Louis J, Manson JH (1996) Number of males in primate groups: comparative tests of competing hypotheses. Am J Primatol 38:315-332

Nievergelt CM, Mutschler T, Feistner ATC, Woodruff DS (2002) Social system of the Alaotran gentle lemur (Hapalemur griseus alaotrensis): genetic characterization of group composition and mating system. Am J Primatol 57:157-176

Nunn CL (1999) The number of males in primate social groups: a comparative test of the socioecological model. Behav Ecol Sociobiol 46:1-13

Ohsawa H, Inoue M, Takenaka O (1993) Mating strategy and reproductive success of male patas monkeys (Erythrocebus patas). Primates 34:533-544

Ostner J, Kappeler PM (2004) Male life history and the unusual adult sex ratios of redfronted lemur, Eulemur fulvus rufus, groups. Anim Behav 67:249-259

Pereira ME, Kappeler PM (1997) Divergent systems of agonistic relationship in lemurid primates. Behaviour 134:225-274

Pereira ME, Leigh SR (2003) Modes of primate development. In: Kappeler PM, Pereira ME (eds) Primate life histories and socioecology. Chicago University Press, Chicago, pp 149-176

Plavcan JM (2001) Sexual dimorphism in primate evolution. Yearb Phys Anthropol 44:25-53

Pochron ST, Wright PC (2003) Variability in adult group compositions of a prosimian primate. Behav Ecol Sociobiol 54:285-293

Pochron ST, Wright PC (2005) Testes size and body weight in the Milne-Edwards' sifaka (Propithecus edwardsi) of Ranomafana National Park, Madagascar, relative to other strepsirhine primates. Folia Primatol 76:37-41

Pochron ST, Fitzgerald J, Gilbert CC, Lawrence D, Grgas M, Rakotonirina G, Ratsimbazafy R, Rakotosoa R, Wright PC (2003) Patterns of female dominance in Propithecus diadema edwardsi of Ranomafana National Park, Madagascar. Am J Primatol 61:173-185

Pope TR (1990) The reproductive consequences of male cooperation in the red howler monkey: paternity exclusion in multi-male and single-male troops using genetic markers. Behav Ecol Sociobiol 27:439-446

Reeder DM (2003) The potential for cryptic female choice in primates: behavioral, anatomical, and physiological considerations. In: Jones CB (ed) Sexual selection and reproductive competition in primates: new perspectives and directions. American Society of Primatologists, Norman, OK, pp 255-302

Reeve HK, Keller L (2001) Test of reproductive-skew models in social insects. Annu Rev Entomol 46:347-385

Reeve HK, Ratnieks FLW (1993) Queen-queen conflict in polygynous societies: mutual tolerance and reproductive skew. In: Keller L (ed) Queen number and sociality in insects. Oxford University Press, Oxford, pp 45-85

Reeve HK, Shen S-F (2006) A missing model in reproductive skew theory: the bordered tug-of-war. Proc Natl Acad Sci USA 103:8430-8434

Reeve HK, Emlen ST, Keller L (1998) Reproductive sharing in animal societies: reproductive incentives or incomplete control by dominant breeders? Behav Ecol 9:267-278
Richard AF (1987) Malagasy prosimians: female dominance. In: Smuts BB, Cheney DL, Seyfarth RM, Wrangham RW, Struhsaker TT (eds) Primate societies. University of Chicago Press, Chicago, pp 25-33

Richard AF (1992) Aggressive competition between males, femalecontrolled polygyny and sexual monomorphism in a Malagasy primate, Propithecus verreauxi. J Hum Evol 22:395-406

Richard AF, Heimbuch R (1975) An analysis of the social behavior of three groups of Propithecus verreauxi. In: Tattersall I, Sussman RW (eds) Lemur biology. Academic, New York, pp 313-333

Richard AF, Nicoll ME (1987) Female social dominance and basal metabolism in a Malagasy primate, Propithecus verreauxi. Am J Primatol 12:309-314

Richard AF, Rakotomanga P, Schwartz M (1993) Dispersal by Propithecus verreauxi at Beza Mahafaly, Madagascar: 19841991. Am J Primatol 30:1-20

Richard AF, Dewar RE, Schwartz M, Ratsirarson J (2002) Life in the slow lane? Demography and life histories of male and female sifaka (Propithecus verreauxi verreauxi). J Zool 256:421-436

Setchell JM (2003) The evolution of alternative reproductive morphs in male primates. In: Jones CB (ed) Sexual selection and reproductive competition in primates: new perspectives and directions. American Society of Primatologists, Norman, OK, pp 413-436

Sorg JP, Ganzhorn JU, Kappeler PM (2003) Forestry and research in the Kirindy Forest / Centre de Formation Professionnelle Forestière. In: Goodman SM, Benstead JP (eds) The natural history of Madagascar. University of Chicago Press, Chicago, pp 1512-1519

Thoren S, Lindenfors P, Kappeler PM (2006) Phylogenetic analyses of dimorphism in primates - evidence for stronger selection on canines than on body size. Am J Phys Anthropol 130:50-59

Trivers RL (1974) Parent-offspring conflict. Am Nat 14:249-264

Utami SS, Goossens B, Bruford MW, de Ruiter JR, van Hooff JARAM (2002) Male bimaturism and reproductive success in Sumatran orang-utans. Behav Ecol 13:643-652

van Schaik CP, Hörstermann M (1994) Predation risk and the number of adult males in a primate group: a comparative test. Behav Ecol Sociobiol 35:261-272

van Schaik CP, Kappeler PM (1996) The social systems of gregarious lemurs: lack of convergence with anthropoids due to evolutionary disequilibrium? Ethology 102:915-941

Vehrencamp SL (1983) A model for the evolution of despotic versus egalitarian societies. Anim Behav 31:667-682

Vick LG, Pereira ME (1989) Episodic targeting aggression and the histories of lemur social groups. Behav Ecol Sociobiol 25:3-12

Widdig A, Bercovitch FB, Streich WJ, Sauermann U, Nürnberg P, Krawczak M (2004) A longitudinal analysis of reproductive skew in male rhesus macaques. Proc R Soc Lond, B Biol Sci 271:819-826

Williams GC (1966) Adaptation and natural selection. Princeton University Press, Princeton, NJ

Wimmer B (2000) Untersuchung der Paarungssysteme und der Populationsstruktur von Lemuren an Coquerel's Zwergmausmaki (Mirza coquereli), dem grauen Mausmaki (Microcebus murinus), dem Rotstirnmaki (Eulemur fulvus rufus) und dem Larvensifaka (Propithecus verreauxi verreauxi). Ph.D. thesis, Ludwig Maximilians-Universität, München

Wimmer B, Kappeler PM (2002) The effects of sexual selection and life history on the genetic structure of redfronted lemur, Eulemur fulvus rufus, groups. Anim Behav 63:557-568

Wright PC (1999) Lemur traits and Madagascar ecology: coping with an island environment. Yearb Phys Anthropol 42:31-72

Young AJ, Carlson AA, Monfort SL, Russell AF, Bennett NC, CluttonBrock T (2006) Stress and the suppression of subordinate reproduction in cooperatively breeding meerkats. Proc Natl Acad Sci USA 103:12005-12010 